\title{
Professionalism in Medical Journalism and Role of HEC, PM\&DC
}

The art of medical writing and science of scientific publishing has made tremendous progress during the last two decades. The revolution in information technology while on one hand has brought lot of ease and benefits, it has also created tremendous pressure and problems for the medial editors who are trying to come up to the expectations of authors who are very keen to see their manuscript published soon after submis-sion. ${ }^{1,2}$

One can be a good physician or a good surgeon but it does not mean that he/she can also be a good Editor as one has to learn this art. That is why starting with the International Committee of Medial Journal Editors (ICMJE) $)^{3,4}$ which was formed in 1978 and later World Association of Medical Editors formed in $1995^{5}$ have been working to improve the professional skills of medial editors by regularly organizing conferences, Hands on Workshops as well as seminars to train the editors. Their websites offer lot of useful information and training material. American Medial Writers Association (AMWA), ${ }^{6}$ European Medical Writers Association (EMWA) ${ }^{7}$ and European Association of Science Editors (EASE) ${ }^{8}$ founded in 1982 have also been doing a commendable job helping the authors and researchers. They too organize their annual conferences and training workshops on regular basis. Then came the various regional bodies like Eastern Mediterranean Association of Medical Editors (EMAME) and Asia - Pacific Association of Medial Editors (APAME) which have been busy in promoting the discipline of medical journalism in their respective regions. ${ }^{9,10}$ Numerous countries in these regions have also formed their own associations of medical journal editors to improve the professional capacity of their member editors in their respective countries. Pakistan which had taken an active part in establishing the EMAME in 2003 did not lag behind and established Pakistan Association of Medial Editors (PAME) in 2010. Since then it has not only hosted EMMJ5 Medical Journals Conference in 2010 which was attended by thirty four foreign delegates and guest speakers from eighteen countries but has also organized three national conferences and a large number of Hands on Workshops all over the country. ${ }^{11}$

PAME organized training course for medical journal editors at Karachi on July 14, 2012, at PIMS Islamabad on September 15, 2012, at Khyber Medical University at Peshawar in Khyber KPK on September 16, 2012 and at University of Health Sciences Lahore on April 25, 2013. PAME organized yet another training course for medical journal editors at University of Health Sciences Lahore on March 4-5 ${ }^{\text {th }}$ 2016. All this was aimed at to build up the professional capacity of editors of biomedical journals published from Pakistan.

Journalology has now emerged as an important discipline with numerous sub-specialties. Publishing a good quality peer reviewed journal is an uphill task which requires a team work. Publishing a medical journal is not economically viable for many institutions and organizations. The problems are further compounded with the non-availability of good Peer Reviewers, willing and interested Editorial Board Members which play a vital role in improving the contents and quality of a journal. If this was not all, the issues like plagiarism, scientific misconduct and upholding professional ethics has made the job of the editors more difficult. Institutions like Committee on Publication Ethics (COPE) UK has come up with very informative Flow Charts to guide the editors on dealing with scientific misconduct including plagiarism, duplicate and redundant publication etc., but it has not made the life of medical journal editors easy. ${ }^{12}$ It is extremely important that one should opt for professionalism, seeks help and assistance from the respective government institutions, organizations to find a solution to the various problems with the medical journal editors are facing. It was in this context that PAME in its Third National Conference held at UHS Lahore from April 1 - 2, 2016 had devoted a special session 
to "Professionalism and Medical Journal Editors" where representatives of Higher Education Commission (HEC) and Pakistan Medical and Dental Council (PM\&DC) were also invited. However, it was unfortunate that none of them came to attend the meeting thus deprived themselves to update on latest developments and problems faced by Editors.

Some of the issues concerning both these institutions which were highlighted during the conference were as under:

\section{Pakistan Medical and Dental Council}

1. Its website is not updated regularly.

2. List of PM\&DC recognized journals is not update and lacks lot of information and there is no mention of Publication Ethics.

3. There is a communication gap between the PM\& DC and the Editors. Not enough time is given when asking for some documents or holding meeting of Journals Evaluation Committee.

4. Communications sent to the PM\&DC remain unanswered and it makes no differentiation between those journals who fulfill all the requirements, are published regularly and those who do not follow the laid down criteria.

5. Communications received from the Journals Committee of PM\&DC from time to time have a threatening tone and they need to show respect to the Editors.

6. PM\&DC wants the journals to submit plagiarism report but provides no help or assistance to the journals in this regard.

\section{Higher Education Commission}

1. Communications received from Quality Assurance Department regarding meeting of Journal Evaluation Committee does not give enough time.

2. In the past HEC used to provide the facility of che-cking manuscripts for plagiarism using the Turni-tin software but now it has been restricted to med-ical universities only.

3. HEC website is also not updated regularly.

4. Communication gap between the HEC and Medial Journal Editors also needs improvement.

It will be unfair not to mention the generous grant the Higher Education Commission has been providing to its recognized biomedical journals for the last many years but it will be much better if it is replaced by providing much needed services and software facilities.

Pakistan Association of Medical Editors with its meager resources has been doing a commendable job to help improve the professional capacity of Editors through various ways. Its website also contains some useful material for the training of the new editors. ${ }^{11}$ Regulatory bodies like PM\&DC and HEC working in close collaboration with PAME can work wonders and go a long way in improving the standard of biomedical journals published from Pakistan. Commission on Iranian Medical Journals based in Ministry of Health in Islamic Republic of Iran apart from providing financial assistance also provides software for checking plagiarism, helps the journal in preparing their websites, helps them provide facilities of XML which has helped a large number of Iranian Medical Journals to go to PubMed Central and has thus increased their visibility and readership manifold. The number of medical journals published from Iran was ninety in 2005 which has now increased to over four hundred. Seventy two of these Iranian Medical Journals are visi-ble on PubMed, PubMed Central and Medline while twenty are covered by ISI Thompson Reuter known for Impact Factor. ${ }^{13}$ On the contrary only about half a dozen medical journals from Pakistan are covered by Medline, PubMed and PubMed Central and only four medical journals from Pakistan has an Impact Factor. ${ }^{14}$

Our regulatory bodies can learn from Iran and that is what the HEC should be doing in Pakistan. Instead of offering any financial grants it can better utilize the same resources to provide facilities for checking plagiarism, software to prepare XML files for submission to PubMed Central, organizing training workshops for Editors and support staff on Open Journal System, electronic publishing, peer review, publication ethics etc. PAME has the professional capacity to help PM\&DC and HEC to realize these objectives. What is missing is the proper liaison and understanding between Medical Journal Editors and these regulatory bodies like PM\& DC and HEC. A study presented at the PAME Third National Conference by the author had also heighted some basic and serious deficiencies in the journals which are recognized by PM\&DC as well as HEC bec-ause the members of their respective Journal Evaluat-ion Committees are not fully conversant with the latest developments in the field of 
medical journalism. These committees need to be further strengthened by induct-ing competent, knowledgeable professional editors and PAME has time and again offered its help and assis-tance in this regard. Even once the PM\&DC had also issued a notification making PAME President an ex-offico member of the Journals Evaluation Committee but no meeting was ever held. ${ }^{15}$

To improve the present situation and find a workable, feasible, practical solution to the various problems being faced by the medical journal editors in Pakistan is not an uphill task. The objective of every one, the editors and regulatory bodies like PM\&DC and HEC are the same i.e. improvement in the quality of contents, standard of medical journals so that we can increase our contribution to the world medical lite-rature and promote research culture in Pakistan. Intent-ions of everyone are good but what is lacking is co-operation, co-ordination and bridging the communicat-ion gap. It is never too late and let us makes a new be-ginning in our relationship. The role of the regulatory bodies is to facilitate and not to create hurdles and dis-courage those who are working under difficult circum-stances with meager resources and facilities available.

\section{References}

1. Jawaid SA, Jawaid M. Are the Editors faced with eproblems performing their duties and responsibilities satisfactorily? Pak J Med Sci. 2013; 29 (5): 1087-1092.

2. Jawaid SA. Authors- the most dangerous pressure group. Pak J Med Sci. 2014; 30 (6): 1177-1179. doi: http://dx.doi.org/10.12669/pjms.306.6465

3. Lang TA. How to Write, Publish and Present in the Health Sciences: A Guide for Clinicians and Laboratory Researchers. Published by American College of Physicians, Philadelphia, USA, 2009: Page: 6-7.

4. International Committee of Medical Journal Editors. www.icmje.org Accessed on May 20 2016.

5. World Association of Medical Editors. http://www.wame.org/ Accessed on May 22, 2016.

6. American Medical Writers Association. http://www.amwa.org/ Accessed on May 21, 2016.

7. European Medical Writers Association. http://www.emwa.org/ Accessed on May 22, 2016.

8. European Association of Science Editors. http://www.ease.org.uk/ Accessed on May 22, 2016.

9. Eastern Mediterranean Association of Medical Editors. http://www.emro.who.int/entity/emame/ Accessed on May 23, 2016.

10. Asia Pacific Association of Medial Editors. http://www.wpro.who.int/apame/en/ Accessed on May 23, 2016.

11. Pakistan Association of Medial Editors. http://www.pame.org.pk Accessed on May 22, 2016.

12. Committee on Publication Ethics, (COPE) UK. http://publicationethics.org/ Accessed on May 23, 2016.

13. Jawaid SA. Proceedings of EMMJ6 Medical Journal Conference held at Shiraz, Iran February 18 - 20, 2015. Pak J Med Sci. 2015; 31 (3): 726-736.

14. ISI Web of Knowledge. Journal Citation Report 2014. Thompson Reuter. http://thomsonreuters.com/en/productsservices/scholarly-scientific-research/researchmanagement-and-evaluation/journal-citationreports.html

15. PM\&DC Notification No. PF.12-F-2012 (Journal)/233642 Dated April 25, 2012.

Shaukat Ali Jawaid Chief Editor Pakistan Journal of Medical Sciences, Karachi, Pakistan. 